\title{
Simultaneous Determination of Nickel and Cadmium by Differential Pulse Polarography
}

\author{
Rodrigo Mayén-Mondragón,* Alejandro BaEza,** and Jorge G. Ibanez*† \\ *Depto. de Ciencias, Universidad Iberoamericana, Prol. Paseo de la Reforma \#880, \\ 01210 México, D. F. México \\ **Facultad de Química, Universidad Nacional Autónoma de México, Circuito Exterior, Ciudad Universitaria, \\ 04510 México, D. F. México
}

(Received August 31, 2001; Accepted October 3, 2001)

Spent nickel-cadmium batteries have become an environmental inconvenience, and many efforts have been undertaken to treat or dispose of them in a safe way. ${ }^{1,2}$ Research has been performed for the selective electrodeposition of nickel and cadmium from simulated waste solutions. ${ }^{3}$ Work is being carried out in our laboratory with a similar objective.

There is an obvious need to analyze both metal concentrations simultaneously and continuously with a fast and precise analytical method in the concentration range of interest. Whereas cadmium is not normally an analytical problem, many different analytical techniques have been proposed for the analysis of $\mathrm{Ni}$, such as spectrophotometry, ${ }^{4-9}$ atomic absorption, ${ }^{10,11}$ flame emission, ${ }^{12,13}$ and ion exchange. ${ }^{14}$ However, most of these require pieces of somewhat expensive equipment and time-consuming sample preparation procedures. The electrochemical analysis of small amounts of nickel requires relatively inexpensive equipment but presents certain difficulties due to its irreversible reduction behavior. ${ }^{15,16}$ In spite of this, it has been successfully accomplished using a variety of techniques such as stripping and voltammetric analysis, ${ }^{17-22}$ polarography, ${ }^{16,23-27}$ and potentiometry. ${ }^{28}$

To the best of our knowledge, the simultaneous analysis of $\mathrm{Ni}$ and $\mathrm{Cd}$ by differential pulse polarography has not been reported yet. The present work reports on the conditions found suitable to perform such an analysis in the same matrix by slow sweep differential pulse polarography on a controlled-growth mercury electrode (CGME) in the concentration range of $10^{-4}$ to $10^{-5} \mathrm{M}$ for both species. In addition to the simplicity of the analytical procedure, the transfer of the analyte to the polarographic cell is straightforward and does not require a special preparation protocol. The precision obtained in the $\mathrm{Ni}$ analysis is similar to, or even higher than, that of most of the procedures mentioned earlier, and that of $\mathrm{Cd}$ is also found to be very high.

\section{Experimental}

A CV-50W voltammetric analyzer (Bioanalytical Systems, BAS) was coupled to a controlled growth (triply-distilled) mercury electrode (CGME, BAS) in a three-electrode cell. The reference electrode was $\mathrm{Ag} / \mathrm{AgCl}$ (MF 2052, BAS), and a

\footnotetext{
$\dagger$ To whom correspondence should be addressed

E-mail: jorge.ibanez@uia.mx
}

square-shaped piece of platinum (Strem Chemicals, 99.9\%, area $=1 \mathrm{~cm}^{2}$ ) was the counter-electrode. All solutions were prepared with demineralized water (Theissier Demineralized Water) passed through a deionization system (Aries Vaponics). A buffer solution of $1 \mathrm{M}$ ammonium citrate (Baker Analyzed Reagent) and $1 \mathrm{M}$ ammonium hydroxide (Baker Analyzed Reagent, 28.2\%) was used to produce a $\mathrm{pH}$ value of 10 . The sample solution was prepared with $1 \mathrm{M}$ sodium sulfate (Baker Analyzed Reagent) as supporting electrolyte, $2.05 \times 10^{-3} \mathrm{M}$ cadmium sulfate (Baker Analyzed Reagent) and $5.93 \times 10^{-3} \mathrm{M}$ nickel sulfate (Sigma). Prior to each experiment, high purity nitrogen was passed through a wash bottle filled with pure water and then bubbled through the target solution for $5 \mathrm{~min}$ to deaerate the system. A blanket of the same gas was kept over the solution for the duration of the experiments. The polarograph was operated with a pulse amplitude of $50 \mathrm{mV}$, sample width of $17 \mathrm{~ms}$, pulse width of $50 \mathrm{~ms}$, and drop time of $1000 \mathrm{~ms}$. Runs were made in triplicate with 7 different concentrations of both metals in the range of $10^{-5}$ to $10^{-4} \mathrm{M}$. These solutions were prepared by adding appropriate volumes (from 50 to $500 \mu \mathrm{L}$ ) of the sample solution with an Eppendorf automatic delivery pipet to $5 \mathrm{~mL}$ of the buffer solution.

\section{Results and Discussion}

The analysis of cadmium (in cadmium-only containing solutions) was successfully accomplished in our laboratory by sampled current polarography, giving a linear variation of the diffusion limiting current with the concentration of the metal in solution. Unfortunately, the analysis of nickel in this manner gave quite erratic results. DPP analysis of nickel has been accomplished earlier by using a $0.1 \quad \mathrm{M}$ ammonium citrate/ammonium hydroxide buffer. ${ }^{16}$ By following this procedure, we obtained the results shown in Fig. 1. In the presence of $\mathrm{Cd}(\mathrm{II})$, a severe distortion of the nickel DPP peak can be noticed upon increasing the cadmium concentration. Such a distortion can be interpreted in the light of the corresponding predominance-zone diagram for the $\mathrm{Ni}(\mathrm{II})-\mathrm{NH}_{3}$-citrate system at $\mathrm{pH}=10$ (see Fig. 2). ${ }^{29}$ It can be seen that with our initial working concentrations (see Experimental section above) the equilibrium is located at $\mathrm{pNH}_{3}$ $=1$ and $\mathrm{pCit}=\mathrm{pL}=1$, which is very close to the intersection of three different predominance zones. We interpret this to be the 


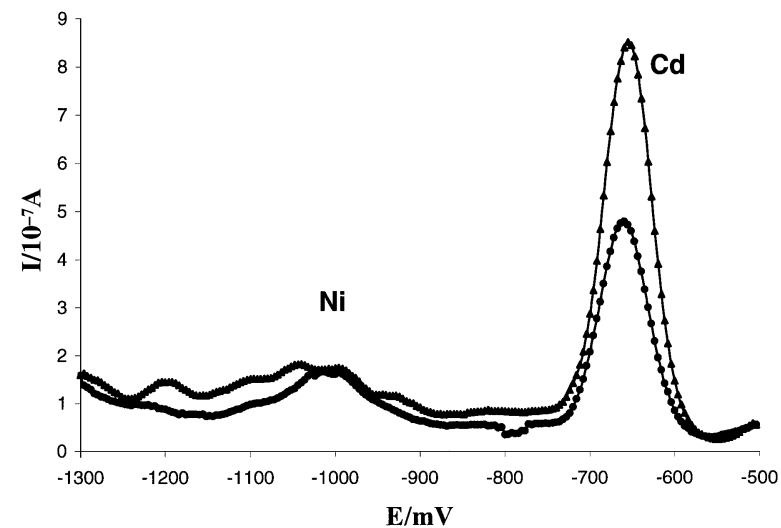

Fig. 1 Distortion of the nickel reduction peak obtained by differential pulse polarography in a solution containing $0.1 \mathrm{~mol} \mathrm{~L}^{-1}$ ammonium citrate $/ 0.1 \mathrm{~mol} \mathrm{~L}^{-1}$ ammonium hydroxide as buffer and: •, $8.76 \times 10^{-5} \mathrm{~mol} \mathrm{~L}^{-1} \mathrm{NiSO}_{4}+3.02 \times 10^{-5} \mathrm{~mol} \mathrm{~L}^{-1} \mathrm{CdSO}_{4} ; \mathbf{\Lambda}, 1.72 \times$ $10^{-4} \mathrm{~mol} \mathrm{~L}^{-1} \mathrm{NiSO}_{4}+5.97 \times 10^{-5} \mathrm{~mol} \mathrm{~L}^{-1} \mathrm{CdSO}_{4}$. Sweep rate: $4 \mathrm{mV}$ $\mathrm{s}^{-1}$.

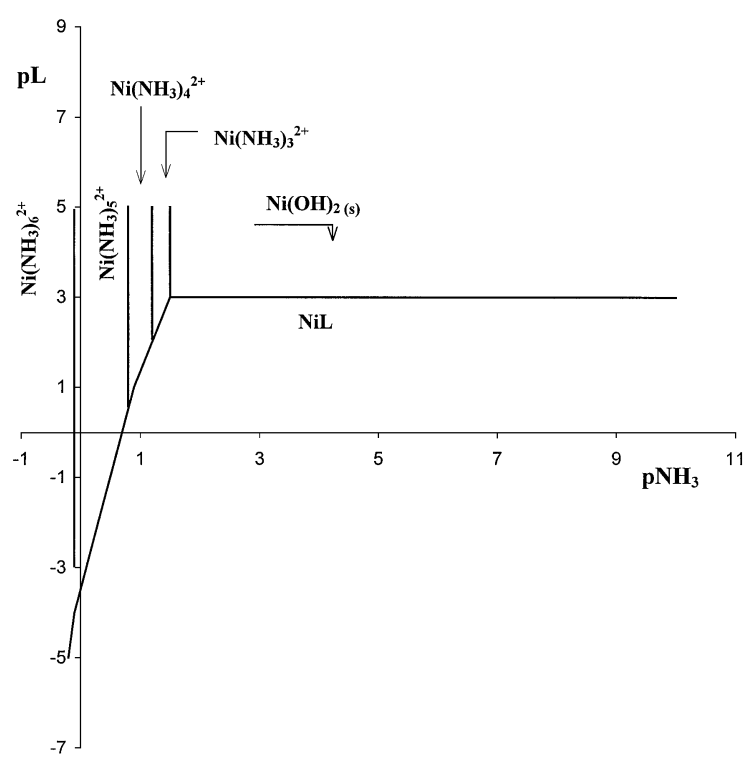

Fig. 2 Predominance-zone diagram for the system $\mathrm{Ni}(\mathrm{II})-\mathrm{NH}_{3}-\mathrm{L}$ (L $=$ citrate) at $\mathrm{pH}=10$ and $\mathrm{pNi}=4$.

explanation for the observed distortions. In the same manner, from the diagram for the $\mathrm{Cd}(\mathrm{II})-\mathrm{NH}_{3}$-Cit system (calculated at $\mathrm{pH}=10$, see Fig. 3 ) it can be deduced that $\mathrm{Cd}(\mathrm{II})$ is stable as a single species $\left(\mathrm{CdL}_{2}\right)$. To promote a better peak definition, we then increased the concentration of the buffer so as to provide a larger amount of ammonia ligands, since it is known that complexation may enhance the reversibility of $\mathrm{Ni}$ (II) electrode processes. ${ }^{16}$ The nickel peak definition was indeed enhanced by this procedure (see Fig. 4). Unfortunately, such a modification also provoked a displacement of the cadmium peak potential to more negative values, indicating the formation of cadmium complexes with higher coordination numbers (in this case $\left.\left[\mathrm{Cd}\left(\mathrm{NH}_{3}\right)_{5}\right]^{2+}\right)$, whose reduction is more difficult to achieve. ${ }^{30} \mathrm{In}$ addition, the cadmium peak current decreased with an increase in buffer concentration. This has been interpreted as a result of the decrease in the diffusion coefficient as the coordination number in the complex increases. ${ }^{30}$ Since the nickel peak height remained essentially constant and its shape became better

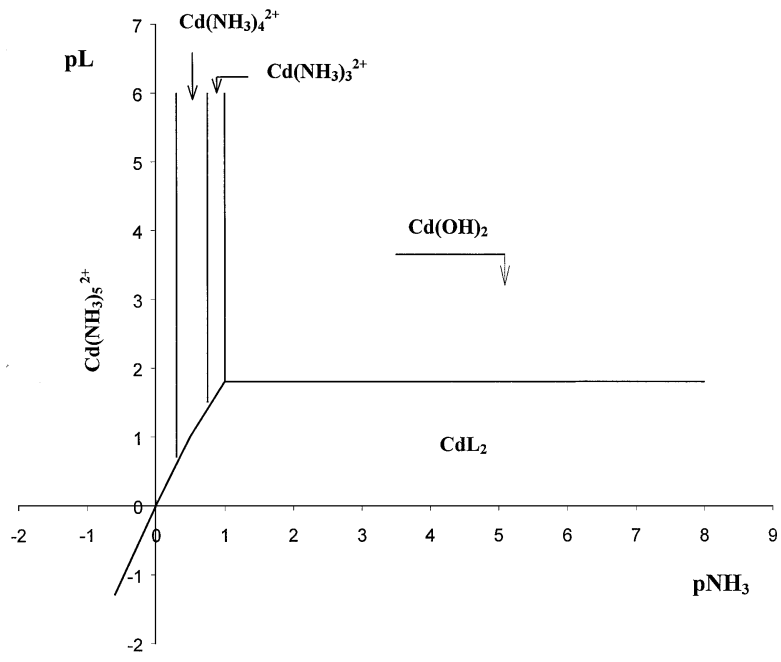

Fig. 3 Predominance-zone diagram for the system $\mathrm{Cd}(\mathrm{II})-\mathrm{NH}_{3}-\mathrm{L}$ ( $\mathrm{L}$ $=$ citrate) at $\mathrm{pH}=10$ and $\mathrm{pCd}=4$.

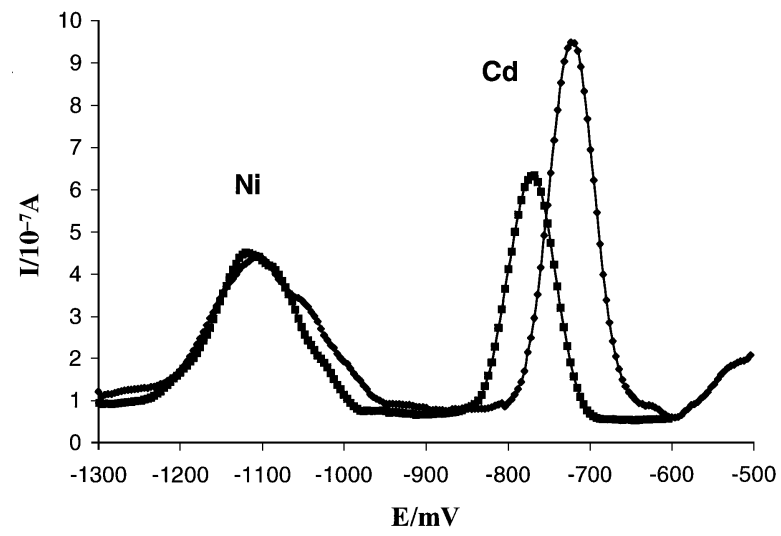

Fig. 4 Displacement of the cadmium reduction peak potential obtained by differential pulse polarography in: $\bullet .72 \times 10^{-4} \mathrm{~mol} \mathrm{~L}^{-1}$ $\mathrm{NiSO}_{4}+5.97 \times 10^{-5} \mathrm{~mol} \mathrm{~L}^{-1} \mathrm{CdSO}_{4}+0.5 \mathrm{~mol} \mathrm{~L}^{-1}$ ammonium hydroxide $/ 0.5 \mathrm{~mol} \mathrm{~L}^{-1}$ ammonium citrate; $\mathbf{\square}, 1.72 \times 10^{-4} \mathrm{~mol} \mathrm{~L}^{-1}$ $\mathrm{NiSO}_{4}+5.97 \times 10^{-5} \mathrm{~mol} \mathrm{~L}^{-1} \mathrm{CdSO}_{4}+1 \mathrm{~mol} \mathrm{~L}^{-1}$ ammonium hydroxide/ $1 \mathrm{~mol} \mathrm{~L}^{-1}$ ammonium citrate. Sweep rate: $4 \mathrm{mV} \mathrm{s}^{-1}$.

defined, under these conditions there is a single species present of each metal, $\left[\mathrm{Ni}\left(\mathrm{NH}_{3}\right)_{6}\right]^{2+}$ and $\left[\mathrm{Cd}\left(\mathrm{NH}_{3}\right)_{5}\right]^{2+}$, as can be observed in the corresponding diagrams (Figs. 2 and 3).

We then increased the concentration of the buffer to $1 \mathrm{M}$ and performed each measurement with fresh buffer instead of adding subsequent amounts of the sample solution to the same buffer solution. This new procedure yielded very well-defined and highly reproducible peaks for both metals, as can be seen in Fig. 5. In fact, the averages of the relative standard deviations of $I_{\mathrm{p}}$ for three replicate runs of each of the seven concentrations tested in the range: $\left[\mathrm{Ni}^{2+}\right]=0.6-5.4 \times 10^{-4} \mathrm{M}$, and $\left[\mathrm{Cd}^{2+}\right]=0.2$ $-1.9 \times 10^{-4} \mathrm{M}$, gave $2.64 \%$ for $\mathrm{Ni}^{2+}$ and $1.58 \%$ for $\mathrm{Cd}^{2+}$. The main sources for such deviations are: drop size variations, baseline determination, and curve adjustment variations (the instrument performs the last two operations automatically). The plots of the average peak current $v s$. concentration resulted in highly linear relationships, with the following regression equations and correlation coefficients:

a) For $\mathrm{Ni}: I_{\mathrm{p}}, \mu \mathrm{A}=0.2041\left[\mathrm{Ni}^{2+}\right] / 10^{-4}-0.0449, R^{2}=0.9985$ 


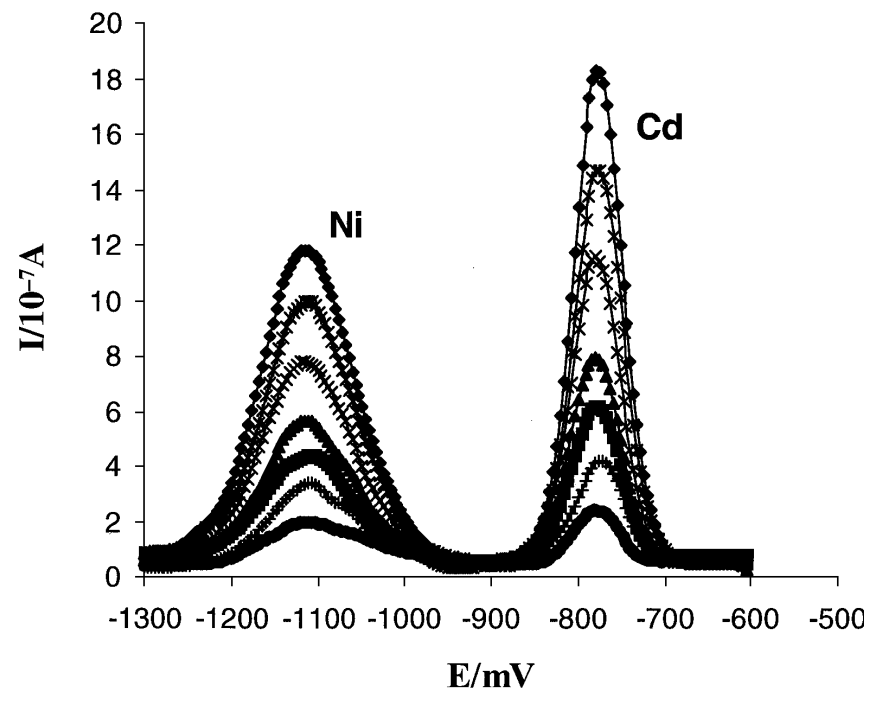

Fig. 5 Variation of the DPP peak current with concentration for the cadmium and nickel reduction polarograms in a $1 \mathrm{~mol} \mathrm{~L}^{-1}$ ammonium hydroxide $/ 1 \mathrm{~mol} \mathrm{~L}^{-1}$ ammonium citrate buffer solution and: $\bullet, 5.87 \times$ $10^{-5} \mathrm{M} \mathrm{NiSO}_{4}+2.02 \times 10^{-5} \mathrm{M} \mathrm{CdSO}_{4} ;+, 1.16 \times 10^{-4} \mathrm{M} \mathrm{NiSO}_{4}+$ $4.01 \times 10^{-5} \mathrm{M} \mathrm{CdSO}_{4} ; \boldsymbol{\square}, 1.72 \times 10^{-4} \mathrm{M} \mathrm{NiSO}_{4}+5.97 \times 10^{-5} \mathrm{M}$ $\mathrm{CdSO}_{4} ; \boldsymbol{\Delta}, 2.28 \times 10^{-4} \mathrm{M} \mathrm{NiSO}_{4}+7.88 \times 10^{-5} \mathrm{M} \mathrm{CdSO}_{4} ; \times, 3.35 \times$ $10^{-4} \mathrm{M} \mathrm{NiSO}_{4}+1.16 \times 10^{-4} \mathrm{M} \mathrm{CdSO}_{4} ; *, 4.39 \times 10^{-4} \mathrm{M} \mathrm{NiSO}_{4}+$ $1.51 \times 10^{-4} \mathrm{M} \mathrm{CdSO}_{4} ; \bullet, 5.39 \times 10^{-4} \mathrm{M} \mathrm{NiSO}_{4}+1.86 \times 10^{-4} \mathrm{M}$ $\mathrm{CdSO}_{4}$. Sweep rate: $4 \mathrm{mV} \mathrm{s}^{-1}$.

b) For Cd: $I_{\mathrm{p}}, \mu \mathrm{A}=0.9632\left[\mathrm{Cd}^{2+}\right] / 10^{-4}-0.0141, R^{2}=0.9997$

Lastly, we tested the effect of performing the analysis at a somewhat longer time after the bubbling of nitrogen gas to evaluate possible interferences from other thermodynamic or kinetic phenomena. Our results showed that if this procedure is performed $5 \mathrm{~min}$ after the bubbling is discontinued, the resulting peak currents are on the average $2.2 \%$ lower for $\mathrm{Ni}$ and $1.9 \%$ lower for $\mathrm{Cd}$, probably due to ammonia volatilization. A challenge that remains to be investigated is the response of this system to higher $\left[\mathrm{Cd}^{2+}\right] /\left[\mathrm{Ni}^{2+}\right]$ ratios, since the peak potential of cadmium moves towards that of nickel at higher buffer concentrations (as would be required in this case).

\section{Acknowledgements}

We acknowledge funding from CONACYT (Mexico) and from Universidad Iberoamericana.

\section{References}

1. D. J. Hurd, D. M. Muchnick, M. F. Schedler, and T. Mele,
Feasibility Study for the Implementation of Consumer Dry Cell Battery Recycling as an Alternative to Disposal: "Getting a Charge out of the Wastestream"-Final Report, 1992, Recoverable Resources/Boro Bronx 2000 (R2B2), Inc., New York.

2. OECD Steering Group on Nickel/Cadmium Batteries, "Draft Guidance Document for Developing Successful Systems for the Collection and Recycling of Nickel/Cadmium Batteries", 1998, Mexico.

3. R. D. Armstrong, M. Todd, J. W. Atkinson, and K. Scott, J. Appl. Electrochem., 1996, 26, 379.

4. A. Classen and L. Bastings, Analyst [London], 1966, 91, 725 .

5. D. E. Bodart, Z. Anal. Chem., 1969, 247, 32.

6. R. S. Lokhande and N. A. Degwekar, Orient. J. Chem., 1998, 14, 485.

7. D. Sun, Fenxi Huaxue, 1999, 27, 821.

8. M. Kompany-Zareh, A. Massoumi, and Sh. Pezeshk-Zadeh, Talanta, 1999, 48, 283.

9. A. M. Garcia-Rodriguez, A. Garcia-de Torres, J. M. CanoPavon, and C. Bosch-Ojeda, Talanta, 1998, 47, 463.

10. J. G. Sen-Gupta, Anal. Chim. Acta, 1972, 58, 23.

11. S. Scaccia, Talanta, 1999, 49, 467.

12. E. E. Pickett and S. R. Koirtyohan, Anal. Chem., 1969, 41, 14.

13. S. L. C. Ferreira, A. S. Queiroz, M. G. A. Korn, and A. C. S. Costa, Anal. Lett., 1997, 30, 2251.

14. D. G. Biechler, Anal. Chem., 1965, 37, 1954.

15. R. D. Armstrong, M. Todd, J. W. Atkinson, and K. Scott, J. Appl. Electrochem., 1997, 27, 965.

16. C. J. Flora and E. Nieboer, Anal. Chem., 1980, 52, 1013.

17. J. Wang, J. Wang, W. K. Adeniyi, and S. P. Kounaves, Electroanal., 2000, 12, 44.

18. A. Economou and P. R. Fielden, Talanta, 1998, 46, 1137.

19. V. T. Meryan, R. Mokanu, and N. F. Taragan, J. Anal. Chem. (Transl. of Zh. Anal. Khim.), 1997, 52, 463.

20. C. Colombo and C. M. G. Van der Berg, Int. J. Environ. Anal. Chem., 1998, 71, 1.

21. J. Xu, D. Liu, and S. Zhou, Cailiao Baohu, 1996, 29, 22.

22. X. Zhang, Y. Ren, L. Deng, and Y. Yu, Fenxi Shiyanshi, 1996, 15,65 .

23. J. Maslowska and U. Kijanowicz, Technol. Chem. Spozyw., 1997, 57, 141.

24. J. Bubnik, Glastech. Ber., 1992, 65, 79.

25. Y. Shengshu and Y. Zheng, Rare Metals, 1995, 14, 230.

26. Z. She, Fenxi Huaxue, 1993, 21, 1313.

27. K. Saraswathi, J. Electrochem. Soc. India, 1987, 36, 287.

28. J. Wu, X. Zhang, and Y. Sun, Shandong Jiancai Xueyuan Xиebao, 1996, 10, 14.

29. A. Rojas-Hernandez, M. T. Ramirez, J. G. Ibanez, and I. Gonzalez, Anal. Chim. Acta, 1991, 246, 435.

30. D. R. Crow, "Polarography of Metal Complexes", 1969, Chap. 4, Academic Press, London. 